\title{
A Study to Assess the Prevalence and Reasons of Readmission and Health Practices among Patients with Prolapsed Inter Vertebral Disc (PIVD) in Selected Hospital, Kolkata, West Bengal
}

\author{
Madhuchhanda Das ${ }^{1}$, Subhra Srimani ${ }^{2}$ \\ ${ }^{1,2}$ Tutor, Sister Nivedita University Nursing Institute, Newtown, West Bengal \\ Corresponding Author: Madhuchhanda Das
}

DOI: https://doi.org/10.52403/ijshr.20220119

\begin{abstract}
A descriptive survey was conducted to assess the prevalence and reasons of readmission and health practices among patients with Prolapsed Inter Vertebral Disc (PIVD) in selected hospital, Kolkata, West Bengal. The objectives were to identify the prevalence of readmission of PIVD patients, to find out the reasons of readmission, to assess the stated health practices of the PIVD patients and to determine the association of health practices of readmitted PIVD patients with selected variables in selected hospital, Kolkata. The conceptual framework was based on precede-proceed model of modified Behavioral Theory of Jean Watson. Survey research design was adopted. Convenience sampling technique was used to select 60 readmitted PIVD patients of a tertiary hospital of Kolkata. Interview schedule, record analysis proforma and a checklist were used to collect data regarding demographic and clinical profile of the patients, prevalence and reasons of readmission and health practices respectively. Average percentage of readmission from 2015 to 2017 was 33 . Majority of the patients were readmitted due to low back pain $(35 \%)$ and bladder incontinence (21.66\%). Twenty-four (40\%) respondents gave the history of avoiding regular long travelling, 19 (31.66\%) respondents used to avoid squatting. Nearly half of the respondents $(45 ; 75 \%)$ managed pain by using analgesic tablet. No patient used medicated soft shoes advised during discharge. Thirty-two $(53.33 \%)$ patients used bed made up of hard surface and 18 (30\%) patients used lumbo-sacral
\end{abstract}

belt. Statistically significant associations were found between level of education of the patients and use of lumbo-sacral belt and doing regular exercise and habitat and habit of avoiding squatting and gender and regular exercise habit. The study has implications for nursing practice, education, administration and research. Further studies were recommended depending on the findings of the present study.

Key words: Prolapsed Inter Vertebral Disc (PIVD); Readmission; Prevalence of readmission; Health practice; Reasons of readmission.

\section{INTRODUCTION}

When long ago man forsook the trees to walk upright on the ground, he made novel demands on his lumbosacral spine but the upright posture thrown enormous stress on the spine, particularly during flexion and is undoubtedly responsible for many structural causes of backache such as lumbar disc prolapses. There are a number of medical problems that can affect inter vertebral discs. Inter vertebral discs are tough fibrous pads joining each of the spinal vertebrae i.e. back bones. Each inter vertebral disc is composed of a tough outer layer of ligament, the annulus fibrosis and a soft gelatinous core. The structure acts as a shock absorber to cushion the vertebrae during the movements 
of spine and to minimise harshness when jumping or running.

A prolapsed disc, also called a spinal disc herniation or a slipped disc, is a medical condition in which the nucleus pulpous is forced out of the centre of the inter vertebral disc through a tear in the annulus fibrous. A prolapsed disc can lead to pain, numbness or tingling similar to that of a limb that has "fallen asleep," muscular weakness, paralysis, or damaged reflexes. However, depending upon the location of the prolapsed disc, there may be no symptoms at all.

Usually, the inter vertebral discs become less flexible with the aging, which increases the risk of injury. However, a prolapsed disc can also occur as a consequence of an injury such as falling, repeated straining, heavy lifting, and also overweight. The main symptom of a prolapsed inter vertebral disc is low back pain.

This is usually something that most people tolerate. It is later on, when they start getting sciatica, which is a really horrible leg pain along the course of the nerve, when they mostly come to realize it.

The irritation or pressure on the nerve next to the spine may also cause pins and needles, numbness or weakness in part of a buttock, leg or foot. The exact location and type of symptoms depends on the nerve affected. It is thought that symptoms mainly occur if the prolapse causes pressure or irritation of a nerve. This does not happen in all cases. Some prolapses may be small, or occur away from the nerves and cause minor, or no symptoms.

Tests such as X-rays or scans can be advised if symptoms persist. In particular, MRI scan can show the site and size of a prolapsed disc. This information is needed if treatment with surgery is being considered.

The best way to prevent bouts of back pain and prolapsed disc is simply to keep active, and do exercise regularly. This means general fitness exercise such as walking, running, swimming etc. There is no firm evidence to say that any particular 'back strengthening' exercises are more useful than simply keeping fit and active. It is also sensible to be 'back aware'. For example, not to lift an object when in an awkward twisting posture.

A prolapsed disc can heal itself with several weeks or months of conservative, non-operative treatment. Although the disc may never return completely to its preherniated state, reabsorption of the extruded portion of the disc is usually sufficient to eliminate neural compression. Since the inner disc material is meant to be sealed off from the rest of the body's tissues, its extrusion alerts the body that there is a foreign substance present and the tissues respond by producing chemicals that break down the extruded portion of the disc so that the material can be reabsorbed by the body.

\section{METHODOLOGY}

Quantitative research approach was adopted to collect data from the readmitted PIVD patients. As the present study is concerned with the identification of prevalence and reasons of readmission and health practices of PIVD patients, descriptive survey is found to be the best and appropriate approach. The variable was prevalence of readmission, reasons of readmission and health practice of readmitted PIVD patient. Demographic variables included age, gender, education, occupation, socioeconomic status, information related to clinical profile of PIVD patients. For this study non probability convenience sampling technique was utilized to select the sample.

\section{Statistical Methods}

Frequency and percentage done according their demographic characteristics, reason of readmission, health practice. Chisquare was computed to find out the association between educational level and using of lumbo -sacral belt and educational level of the patients and habit of doing regular exercise. 
Madhuchhanda Das et.al. A study to assess the prevalence and reasons of readmission and health practices among patients with Prolapsed Inter Vertebral Disc (PIVD) in selected hospital, Kolkata, West Bengal

\section{RESULTS}

Analyzed data showed that maximum numbers of patients were readmitted due to low back pain followed by bladder incontinence, and numbness and radiating pain. Data also reveal that majority of the patients avoids regular long travelling, forward bending and heavy weight lifting. Data also revealed that there is significant association between education and using lumbo sacral belt and doing regular exercise.

Table 1: Frequency and percentage distribution of the PIVD
patients according to the reason of admission
\begin{tabular}{|l|c|c|}
\hline Reasons of readmission & Frequency & Percentage (\%) \\
\hline LBP & 23 & 38.33 \\
\hline Immobility & 3 & 5.00 \\
\hline Numbness & 7 & 11.66 \\
\hline Radiating pain & 7 & 11.66 \\
\hline Difficulty movement & 1 & 1.67 \\
\hline Sciatica pain & 6 & 10.00 \\
\hline Bladder incontinence & 13 & 21.66 \\
\hline LBP, numbness & 4 & 6.67 \\
\hline \multicolumn{3}{|c|}{ Note: Multiple responses } \\
\hline
\end{tabular}

Data present table no 1 show that maximum numbers of patients $(23 ; 38.33 \%)$ were readmitted due to low back pain followed by bladder incontinence (13; $21.66 \%$ ), and numbness and radiating pain (both $7 ; 11.66 \%$ ).

Data presented in table 2 reveal that majority of the patients avoids alcohol (51; $85 \%$ ) and smoking (46; 76\%). 24 patients $(40 \%)$ avoid regular long travelling, 17 (28.33) patients exercise regularly and avoid forward bending.
Table 2: Frequency and percentage distribution of the patients according to their health practices

\begin{tabular}{|l|c|c|}
\hline \multicolumn{1}{|c|}{ Health practice } & Frequency & Percentage \\
\hline Exercises regularly & 17 & 28.33 \\
\hline Avoids forward bending & 17 & 28.33 \\
\hline Avoids squatting & 19 & 31.66 \\
\hline Avoids heavy weight lifting & 16 & 26.66 \\
\hline Avoids regular long travelling & 24 & 40.00 \\
\hline Avoids heavy working lifestyle & 17 & 28.33 \\
\hline Avoids smoking & 46 & 76.00 \\
\hline Avoids alcohol Note: Multiple responses \\
\hline \multicolumn{2}{|c|}{} \\
\hline
\end{tabular}

Data also depict those 19 (31.66\%) patients were used to avoid squatting, 17 $(28.33 \%)$ avoid heavy working lifestyle and 16 patients $(26.66 \%)$ avoid heavy weight lifting.

Table 3: Frequency and percentage distribution of the patients according to their health practices

\begin{tabular}{|l|c|c|}
\hline \multicolumn{1}{|c|}{ Health practice } & Frequency & Percentage \\
\hline Uses belt & 18 & 30.00 \\
\hline Maintains normal sexual activities & 50 & 83.33 \\
\hline Manages pain by cold application & 13 & 21.66 \\
\hline Manages pain by hot application & 8 & 13.33 \\
\hline Manages pain by analgesic tablet & 45 & 75.00 \\
\hline Manages pain by taking rest & 22 & 36.66 \\
\hline Uses bed made up of hard surface & 32 & 53.33 \\
\hline Regular checkup done & 26 & 43.33 \\
\hline \multicolumn{2}{|c|}{ Note: Multiple responses } \\
\hline
\end{tabular}

Data presented in table 3 reveal that maximum numbers of patients $(50 ; 83.33 \%)$ maintained normal sexual life, maximum patients $(45 ; 75 \%)$ managed pain by using analgesic tablet and $22(36.66 \%)$ by taking rest. It is also seen that $26(43.33 \%)$ patients visit doctor's chamber for follow up checkup.

Table 4: Chi square test of association and its significance existing between educational level of the patients and habit of doing regular exercise

\begin{tabular}{|c|c|c|c|c|c|}
\hline $\begin{array}{c}\text { Educational } \\
\text { level }\end{array}$ & \multicolumn{3}{|c|}{$\begin{array}{c}\text { Regular } \\
\text { exercise }\end{array}$} & $\begin{array}{c}\text { Chi square } \\
\text { value }\end{array}$ & Significance \\
\hline & Yes & No & Total & & \\
\hline Up to secondary & 9 & 39 & 48 & 13.78 & Significant \\
\hline Above Secondary & 8 & 4 & 12 & & \\
\hline Total & $\mathbf{1 7}$ & $\mathbf{4 3}$ & $\mathbf{6 0}$ & & \\
\hline \multicolumn{7}{|c}{$[\mathrm{x} 2(1)=10.83 ; \mathrm{p}=0.001]$} &
\end{tabular}

Data presented in table 4 indicate that out of 48 respondents with up to secondary level of education 9 respondents had the habit of doing regular exercise and 39 did not have. On the other hand, out of 12 respondents with above secondary level of education 8 respondents were doing regular exercise and 4 did not.
Chi square test of association was computed between educational level of the patients and their habit of doing regular exercises and the value was found to be statistically significant at 0.001 level of significance. So, it could be concluded that the habit of using of doing regular exercises was dependent on educational level of the patients. 
Table 5: Frequency and percentage distribution of the patients according to their number of readmission and time after discharge

\begin{tabular}{|c|c|c|}
\hline Variable & Frequency & Percentage \\
\hline \multicolumn{3}{|c|}{ Present number of admissions } \\
\hline $2^{\text {nd }}$ time & 44 & 73.33 \\
\hline $3^{\text {rd }}$ time & 16 & 26.67 \\
\hline \multicolumn{3}{|c|}{$\begin{array}{l}\text { Time of readmission after discharge } \\
\text { (In months) }\end{array}$} \\
\hline $12-24$ & 35 & 58.33 \\
\hline $25-36$ & 18 & 30.00 \\
\hline $37-48$ & 4 & 6.67 \\
\hline $49-60$ & 1 & 1.66 \\
\hline $61-71$ & 2 & 3.34 \\
\hline
\end{tabular}

Data present in table 5 depict that maximum number $(44.73 \%)$ of the patient were readmitted for $2^{\text {nd }}$ time and $16(26.6 \%)$ patients had to take admission for the $3^{\text {rd }}$ time.

Data also show that maximum number $(35 ; 58.33 \%)$ of patients were readmitted within 12 to 24 months after discharge and $18(30 \%)$ patients had to be readmitted due to PIVD within 25-36 months of discharge from hospital.

\section{DISCUSSION}

Major finding of the study has been discussed with reference to the results obtained by other studies based on the objectives of the study.

The study was conducted with the core purpose of assessing the prevalence and reasons of readmission and health practices of readmitted PIVD patients. A descriptive survey design was used. The sample included 60 readmitted PIVD patients in selected hospital. On the basis of the objectives of the present study and its findings, a discussion is made in relation to other studies.

In the present study it was revealed that majority $(23.38 .33 \%)$ of the subjects were belonged to the age group of the 46-56 years. These findings are supported by the finding of a similar prospective study conducted by M. Teraguchit et al. (2013) on 975 with PIVD patients. The study showed that 651 patients were men and 324 patients were women with an age range of 21-97 years. The mean age was 67.2 years for men and 66 years for women.15 Another study findings supported this study which was done by J. Jordon (2009) UK on prevalence of herniated disc and found the highest prevalence was among people aged 30-50 years, with a male to female ratio of $2: 1.16$

In this study majority $(41,68.33 \%)$ of the patients were from rural area supported which is supported by the similar study done by R Prasad et al. (2005) on Epidemiological Characteristics of Lumbar

Disc Prolapse in A Tertiary Care Hospital. In that study $71.7 \%$ patients were from rural area and $59.4 \%$ patients were moderate workers. Similarly, the percentage of rural moderate workers

Even among the female patients, most of them $(72.58 \%)$ were rural moderate workers. 25

In this study majority $(50,83.33 \%)$ of the patients suffered from lumber disc herniation which is supported the similar study done by Daoyou Ma, Yunbiao Liang and Zhiyou Cai (2013) to find out whether the incidence of lumber disc herniation increases with age. The aim was to find out the relationship between the process of ageing and occurrence of lumber disc herniation in old adults. The most common site of lumber disc herniation is towards the bottom of the spine at L4-L5 and L5-S1.19

In the present study Majority (28, 46.66) of the patients were unskilled labour. They had to do heavy weight lifting regularly. The finding is supported by similar case-control study done by A Seidler, U Bolm-Audorff et al. (2003) on occupational risk factors for symptomatic lumber disc herniation on 267 samples. The study shows that there is statistically significant positive association between extreme forward bending and heavy weight lifting with lumber disc degeneration. 31

In the present study also revealed that surprisingly no patient was using medicated soft shows, higher the education level more the health compliance, habitat did not make difference in health practices.

\section{Nursing Implication}

The findings of the study can be applicable in various areas of nursing practice, nursing education, nursing 
administration and nursing research. In nursing practice this study will strengthen health education and awareness. It will improve follow up care regimen and prevention of readmission and also, they will have sound knowledge regarding prevention and early detection of PIVD and avoiding readmission of PIVD patient. In nursing education present study will help to develop and update knowledge in curriculum of orthopedic nursing and student may be aware of their role in health promotion and disease prevention in present and future. In addition to existing curriculum, preventive measure should be given stress in practical field. In the field of administration prevalence of readmission can make a concern factor. The policies and procedures can be formulated by nursing administrator according to the need of the people. Also, they can be organizing workshop and continue education for nurse to teach community people.

In nursing research, it can valuable reference in future research also no of research work can be replicated in future.

The study has some limitation like this study was limited to the self- reported health practices by the PIVD patients, the sample of the study was relatively small restricting the generalization of its findings, random sampling was not done as the data collection period was not sufficient and the study setting was in selected hospital. So, this study cannot be generalized.

\section{CONCLUSION}

Based on the result of the current study it can be concluded that the health practices of PIVD patients after discharge are not satisfactory to prevent repeated admissions for the same reason. Lack of knowledge of the patients is an important factor that they are readmitted. Nurse can be involved while giving discharge advice to the patients to enable them to follow an optimum health practice.
Acknowledgement: None

Conflict of Interest: None

Source of Funding: None

Ethical Approval: Approved

\section{REFERENCES}

1. Kuppuswamy S, George C J, Chemmanam M; "Prevalence of Lumbar Disc Herniation and Disc Degeneration in Asymptomatic Indian Subjects". An MRI Based Study; International Journal of Orthopaedics Sciences; 2017; 3:.357360.

2. Abuelnour A, M. Mohammed I A. M; "Prevalence and Distribution of the Intervertebral Disc Herniation in Sudanese". World Journal of Pharmaceutical and Medical Research; 2016; 444-447.

3. Sekharappa V, Amritanand R, Krishnan V, David KS. Lumbosacral transition vertebra: prevalence and its significance. Asian Spine J. 2014;8(1):51-58. doi:10.4184/asj.2014. 8.1.51.

4. Teraguchi M, Yoshimura N, Hashizume $\mathrm{H}$, Muraki S, Yamada H, Minamide A, Oka H, Ishimoto Y, Nagata K, Kagotani R, Takiguchi N, Akune T, Kawaguchi H, Nakamura K, Yoshida M. Prevalence and distribution of intervertebral disc degeneration over the entire spine in a population-based cohort: the Wakayama Spine Study. Osteoarthritis Cartilage. 2014 Jan;22(1):104-10. doi: 10.1016/j.joca.2013. 10.019. Epub 2013 Nov 14. PMID: 24239943.

5. Lee $\mathrm{SH}$, Oh $\mathrm{CH}$, Yoon $\mathrm{SH}$, Park HC, Park CO. Prevalence and geographic distribution of herniated intervertebral disc in Korean 19-year-old male from 2008 to 2009: a study based on Korean conscription -national and geographic prevalence of herniated intervertebral disc in Korean 19YO male-. Yonsei Med J. 2013 Sep; 54(5): 1098-103. doi: 10.3349/ymj.2013. 54.5.1098. PMID: 23918557 ; PMCID: PMC3743194. 
Madhuchhanda Das et.al. A study to assess the prevalence and reasons of readmission and health practices among patients with Prolapsed Inter Vertebral Disc (PIVD) in selected hospital, Kolkata, West Bengal

6. Battié MC, Videman $\mathrm{T}$, Parent $\mathrm{E}$. Lumbar disc degeneration: epidemiology and genetic influences. Spine (Phila Pa 1976). 2004 Dec 1;29(23):2679-90. doi: 10.1097/01.brs. 0000146457.83240.eb. PMID: 15564917.

7. Prasad R, Hoda M, Dhakal M; Epidemiological Characteristics of Lumbar Disc Prolapse in A Tertiary
Care Hospital; The Internet Journal of Neurosurgery; 2005;3 (1);1-5.

How to cite this article: Das M, Srimani S. A study to assess the prevalence and reasons of readmission and health practices among patients with Prolapsed Inter Vertebral Disc (PIVD) in selected hospital, Kolkata, West Bengal. International Journal of Science \& Healthcare Research. 2022; 7(1): 111-116. DOI: https:// doi.org/10.52403/ijshr.20220119

$* * * * * *$ 